\title{
Case Report \\ Migration of Inferior Vena Caval Filter to the Right Atrium: Is any model free of this complication?
}

\author{
H ZAMAN A JALAL Z HAIDER \\ Department of Cardiothoracic Surgery, Mayo Hospital/K.E. Medical College. Lahore \\ ('orrespondence to Dr: Haider Zaman, Associate Professor, Email: drhzaman@hotmail.com
}

The use of inferior vena caval (IVC) filters has been an accepted method for preventing pulmonary embolism, especially in cases where there are contraindications to anticoagulation. However, these filters have numerous potential complications some of which could be life threatening like, thrombosis and migration of the filter. The "Antheor" filter was designed to prevent this complication. Unfortunately, we encountered one patient where it has been unsuccessful in this regard. We therefore, believe that there is no ideal filter and the selection of a filter requires thorough knowledge of the limitations of individual brand.

Key words: IVC filter, migration

The use of inferior vena caval (IVC) filters has been an accepted method for preventing pulmonary embolism, especially in cases where there are contraindications to anticoagulation. These filters have numerous potential complications like, caval perforation, thrombosis and migration. Relatively less common complications include structural breakdown of the filter ${ }^{1.2 .3}$, dueodena-caval fistula.5, migration into the retroperitoneal space $^{6}$ and erosion into the vertebral column ${ }^{7}$. The breakdown of a filter can sometimes lead to migration of broken parts into various organs by embolism or local erosion calling for a major and risky exploration ${ }^{8}$.

The incidence of migration of the whole filter has been reported to be as high as $6 \%{ }^{9}$. This complication has to be managed on cardiopulmonary bypass and therefore raises serious concerns about the safety of a filter. The quality of filter is further judged by its clot trapping efficiency and low frequency of caval thrombosis and migration. The design of the filter has undergone a considerable change in the hope of improving its efficiency. The "Antheor" permanent IVC filter was specifically designed to minimize the chances of migration. We describe a case where it has not been successful.

\section{Case Report}

A 47 years old man who recently had neurosurgery for metastatic melanoma of his frontoparietal lobe, developed multiple episodes of pulmonary embolism. The thrombus extended from the left iliac vein into the IVC. As anticoagulation was contraindicated, an "Antheor" $28 \mathrm{~mm}$ permanent IVC filter was deployed in the IVC through the right femoral vein.

The filter was successful in preventing further episodes of pulmonary embolism. However, two and half week later he developed chest pain, tachycardia, dyspnoea and hypotension suggesting another episode of pulmonary embolism. A chest X-ray showed that the filter had migrated to the right atrium and the patient was transferred urgently to our unit. He was taken to the operation theatre and following a median sternotomy, normothermic cardiopulmonary bypass was established using superior and inferior vena caval cannulae. The right atrium was opened and filter was removed without difficulty. It was covered in thrombus which had been trapped successfully. The pulmonary artery was opened and both branches were explored with Fogarty balloon catheter without any yield of thrombus. The catheter was also passed down the IVC where no thrombus was found. Cardiopulmonary bypass was discontinued after closing the pulmonary artery and the right atrium. Post-operative inotropic support was required for short while due to poor right ventricular performance. He returned to the ward the following day and made an uneventful recovery.

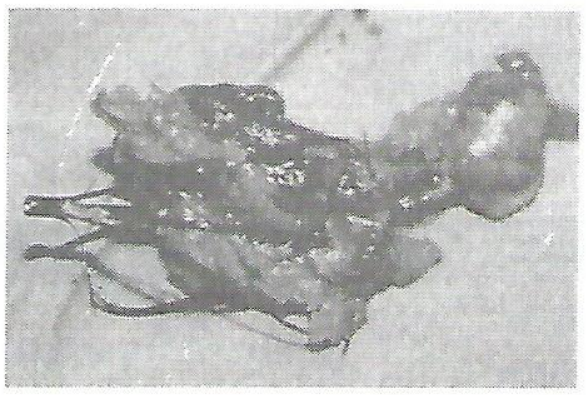

Fig. 1. The IVC filter with trapped clot

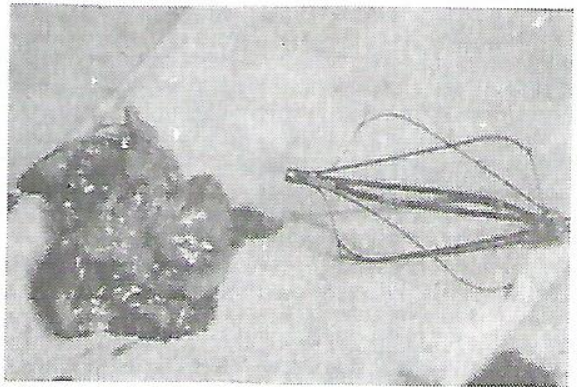

Fig. 2. The filter after removal of clot clearly showing the direction of the lines for stabilization and prevention of migration 


\section{Discussion}

The "Antheor" IVC filter was obviously efficient at trapping thrombus. Although its design is such that its tines face in both directions to minimize migration, it was not successful in this case. The symptoms in this patient could be explained by diminishing return of blood to the heart.

The symmetrical shape of the "Antheor" permanent vena caval filter promotes clot capture and minimize caval patency, but sometimes massive thrombus mass combined with the filter itself forms an obstructive plug in the IVC. The resultant higher pressures in the IVC may play a part in the filter to migrate and stretch of the IVC may dislodge the tines of the filter from the wall. If this mechanism is true it may be difficult for the filter to avoid migration. The design may need to be modified. However, further experience with this filter may allow a better comparison of its efficiency and migration rate with other models.

A large number of caval filters are available in the market including Greenfield filter, Titanium Greenfield filter, Simon-Nitinol filter, Bird's Nest filter, LGM or Vena Tech filter, Amplatz filter and Gunther filter. The availability of such a large number of different designs is itself an evidence that no filter is ideal. There have been reports about the technical difficulties encounter in insertion of these filters as well as the complications after successful insertion. The Greenfield filter is the earliest one and has been reported quite frequently in the literature. Filter migration is one of the commonest complication associated with it. New filters were therefore designed to avoid this complication and Antheor is one of those filters specifically designed to prevent filter migration. Nevertheless, it has failed to achieve this goal in our case report. There are however reports about other available filters with excellent results regarding this problem. Rousseau et al have ${ }^{11}$ have reported their data of 65 patients with a Nitinol permanent IVC filter (Cordis TrapEase). Over a period of six months non of filters migrated from the site of deployment. Poletti el al ${ }^{11}$ have shown similar success rates in 114 cases in an average follow up of 32 months (range 5-62 months) with SimonNitinol inferior vena cava filter. They did not have any case of shunt migration. McCowan et $\mathrm{al}^{12}$ have describe similar success without any filter migration with Amplantz filter in 30 patients. Becker el $\mathrm{al}^{13}$ have provided an excellent review of the problems associated with deployment of caval filters. They reviewed the results reported by different authors published in literature and covers a total of 24 case series out of which 16 were about the Greenfield filter (1632 patients), and eight dealt with other designs (925 patients). They have concluded that although there are still many questions about indication and safety, caval filters are effective in preventing recurrent pulmonary embolism. They have suggested that anticoagulant therapy, if not contraindicated, should be used in conjunction with filters.

\section{Conclusion}

We believe there is no ideal filter. The selection of the filter and method of insertion should be made after consultation between interventional radiologists and surgeons according to the individual clinical situation of the patient.

\section{References}

1. Cabera J J, Macht S.H. Intracaval breakage of umbrella filter. Surgery 1977, 82:255-257

2. Lang $W$, Schweiger H, Fietkau R, Hofmann Preiss $K$. Spontaneous disruption of two Greenfield vena caval filters. Radinlogy 1990 Feb; 174(2):445-6

3. Donovan TJ, Splittgerber FH, Kobberling J, Minale C. Postoperative disruption of an internal prong-type caval filter-a case report.Z. Kardiol $1995 \mathrm{Jul} ; 84(7): 560-4$

4. Guillem PG, Binot D, Dupuy-Cuny J, Laberenne JE, Lesage J, Triboulet JP, Chambon JP. Duodenocaval fistula; a lifethreatening condition of various origins. J Vase Surg 2001;33(3);643-5

5. Appleberg $\mathrm{M}$, Crozier JA. Duodenal penetration by a Greenfield caval filter. Aust N Z J Surg 1991 Dec;61(12):957-60

6. Goldman KA, Adelman MA. Retroperitoneal caval filter as a source of abdominal pain. Cadiovase Surg 1994 Feb;2(1):85-7

7. Shaer JA, Epstein N. An unusual cause of low back pain? A case report. Spine 1998 Jun 15;23(12):1349-50

8. Taheri SA, Kulaylat MN, Johnson E, Hoover E. A complication of the Greenfield filter; fracture and distal migration of two struts-a case report. J Vase Surg 1992 Jul; 16(1):96-9

9. Ferris E J, McCowen TC, Carver DK, McFarland D R Percutaneous inferior vena caval filters: follow-up of seven designs in 320 patients. Radiology 1993; 188(3):851-6

10. Rousseau H, Perreault P, Otal P, Stockx L, Golzarian J, Oliva V, Reynaud P, Raat F, Szatmari F, Santoro G, Emmanuelli G, Nonent M, Hoogeveen Y. The 6-F nitinol TrapEase inferior vena cava filter: results of a prospective multicenter trial. J Vasc Interv Radiol 2001 Mar; 12(3):299.

11. Poletti PA, Becker CD, Prina L, Ruijs P, Bounameaux H, Didier D, Schneider PA, Terrier F. Long-term results of the Simon nitinol inferior vena cava filter. Eur Radiol 1998;8(2):289-94

12. McCowan TC, Ferris EJ, Carver DK, Baker ML. Amplat/ vena caval filter: clinical experience in 30 patients. AJR Am J Roentgenol 1990 Jul:155(1):177-81

13. Becker DM, Philbrick JT, Selby JB. Inferior vena cava filters. Indications, safety, effectiveness. Arch Intern Med 1992 Oct; 152(10): 1985-94 